Keywords: Apathy determinants; Apathy; Amotivation; Depressive disorder; Old age; Geriatric.

\title{
Presence and correlates of apathy in non-demented depressed and non-depressed older persons
}

\author{
Isis Groeneweg-Koolhoven, MD ${ }^{\mathrm{a}, \mathrm{c}, \boldsymbol{}}$ \\ Hannie C. Comijs, $\mathrm{PhD}^{\mathrm{d}}$ \\ Paul Naarding, MD PhDe,f \\ Margot WM. de Waal, $\mathrm{PhD}^{\mathrm{b}}$ \\ Roos C. van der Mast, MD PhD ${ }^{\mathrm{a}, \mathrm{g}}$ \\ a Department of Psychiatry, Leiden \\ University Medical Center, Leiden \\ b Department of Public Health and Primary \\ Care, Leiden University Medical Center \\ c Psychiatry, Hospital Parnassia Group, \\ Rotterdam \\ d Department of psychiatry / EMGO Institute \\ for Health and Care Research, \\ VU University Medical Center and GGZ \\ inGeest, Amsterdam \\ e Department of Old-age psychiatry GGNet \\ Mental Health, Apeldoorn \\ ${ }^{f}$ Department of psychiatry, University \\ Medical Center "St. Radboud", Nijmegen \\ 9 Department of psychiatry, \\ CAPRI-University of Antwerp, Belgium \\ THE NETHERLANDS
}

\begin{abstract}
Background and Objectives: Apathy is a behavioral syndrome that often co-occurs with depression. Nonetheless, the etiology of apathy and depression may be different. We hypothesized that apathy occurs more often in depressed compared to non-depressed older persons; and that independent correlates for apathy will be different in depressed and non-depressed older persons.

Methods: In this cross-sectional study of Netherlands Study of Depression in Older Persons (NESDO), a total of 350 depressed older persons according to the Composite International Diagnostic Interview (CIDI) and 126 non-depressed older persons, aged at least 60 years were recruited in several Medical Centres and general practices.

In both depressed and non-depressed older persons, those with and without apathy as assessed with the Apathy Scale (score $\geq 14$ ) were compared with regard to socio-demographic, clinical, and biological characteristics.

Results: Apathy was present in $75 \%$ of the depressed and $25 \%$ of the non- depressed older persons. Independent correlates of apathy in both depressed and non-depressed older persons were male gender and less education. Furthermore, in depressed older persons, higher scores on the Inventory of Depressive Symptomatology (IDS) and, in non-depressed older persons, a higher C-reactive protein (CRP) level correlated independently with apathy.
\end{abstract}


Conclusions: Apathy occurred frequently among both depressed and non-depressed older persons. Among depressed older persons, apathy appeared to be a symptom of more serious depression, whereas among non-depressed persons apathy was associated with increased CRP being a marker for immune activation, suggesting a different aetiology for apathy in its own right.

Received: 10 December 2014

Revised: 24 April 2015

Accepted: 28 April 2015

\section{Introduction}

Apathy as a distinct, clinically relevant syndrome is a well-known motivational disorder in late life, that is characterized by behavioral, cognitive and emotional symptoms interfering with adequate daily functioning ${ }^{1-3}$. It may occur in community dwelling older persons (1$27 \%)^{4-6}$, as well as in clinical populations with various neuropsychiatric disorders such as dementia $^{3}$, Parkinson's disease ${ }^{2}$ and depression $(42-96 \%)^{7-10}$, then being a very prominent feature of that disorder ${ }^{1-3,11,12}$. Apathy as a distinct clinical syndrome may persist over time and is associated with poor functional outcome, reduced quality of life ${ }^{13}$, poor prognosis and increased overall mortality rates ${ }^{14,15}$.

Little is known about apathy in depressive disorders at old age, since most studies till now examined apathy especially in clinical populations suffering from dementia, stroke and Parkinson's disease, with and without comorbid depressive symptoms ${ }^{11,16-18}$. Although depression and apathy often co-occur, increasing evidence shows that apathy may be a distinct, clinically relevant syndrome with aetiologies possibly different from depression. Recent literature showed that among community-dwelling older persons free from depressive and apathy symptoms at baseline, higher C-reactive protein (CRP) concentrations predicted an increase in depres- sive symptoms but not apathy ${ }^{5}$, whereas cardiovascular disease and cardiovascular risk factors predicted the occurrence of apathy, but not depressive symptoms ${ }^{19,20}$. Also, MRI studies of the brain showed that depression and apathy at old age were both associated with reduced gray matter volumes, but in different areas of the brain ${ }^{12}$.

Further, in 1889 community-based nondepressed older persons without stroke or other cardiovascular disease, increased CRP concentration, assessed as one of the cardiovascular risk factors, was cross-sectionally associated with a higher apathy score ${ }^{20}$. Conversely, in 377 community-based older persons ( $\geq 85$ years), CRP was cross-sectionally nor longitudinally associated with presence of apathy ${ }^{5}$. Thus, the relation between CRP concentration as a marker for immune activation and apathy remains unclear.

To gain more insight into the characteristics of apathy among depressed and non-depressed older persons, this cross-sectional study aimed at investigating the presence and various correlates of apathy as a syndrome in its own right. We hypothesized that apathy occurs more often in depressed older persons and has different independent correlates for apathy than in non-depressed older persons.

We assumed that in depressed older persons apathy would correlate with severity of depression and in non-depressed older per- 
sons, based on the literature, with cognitive impairment, vascular disease, frailty and immune activation.

\section{Method}

\section{Study design}

This cross-sectional study is part of the NEtherlands Study of Depression in Older persons (NESDO), a multi-site naturalistic, 6years prospective cohort study that was designed to examine various determinants, course and consequences of depressive disorders in older persons ( $\geq 60$ years). The full design of this study is described in an earlier report ${ }^{21}$.

Between 2007 and 2010, a total of 378 depressed older persons with a primary diagnosis of major depression, dysthymia or minor depression in the previous 6 months according to DSM-IV criteria (American Psychiatric Association) as assessed with the Composite International Diagnostic Interview (CIDI; WHO version 2.1; life-time version $)^{22}$ were recruited in university medical centers, mental health care institutes and general practitioners. Furthermore a total of 132 control older persons without a life-time diagnosis of depression were recruited from 14 general practices. Exclusion criteria were: a diagnosis of dementia or a Mini Mental State Examination-score (MMSE) under 18; presence of a psychotic disorder; and insufficient mastery of the Dutch language.

The study protocol of the NESDO study has been approved by the Ethical Review boards of all participating centers. Before enrollment all participants gave verbal and written informed consent. For this sub-study, only persons with complete Apathy Scalescores were included resulting in data of 350 depressed and 126 non-depressed older persons for further analyses (see Figure 1).

\section{Measures}

\section{Assessment of apathy}

Apathy was assessed with the Apathy Scale used as a self-report questionnaire ${ }^{23,24}$. The Apathy Scale is an abbreviation of the Apathy Evaluation Scale showing a good one-week test-retest $(r=0.90)$ and inter-rater $(\mathrm{r}=0.81)$ reliability and internal validity in both self-reported and observer-rated measurements ${ }^{23,24}$. The Apathy Scale consists of 14 items with four possible answers ranging from 0-3 points, with higher scores indicating more severe apathy ${ }^{23}$. A score $\geq 14$ points is indicative for the presence of clinically relevant apathy ${ }^{23,25}$.

\section{Assessment of depression and cognition}

Severity of depression was assessed using the 30-item self-report Inventory of Depressive Symptomatology (IDS-SR) ${ }^{26}$, with higher scores indicating more severe depression. Information on global cognitive functioning was assessed with the Mini-Mental State Examination (MMSE) ${ }^{27}$.

\section{Assessment sociodemographic, clinical and biological characteristics}

For all persons the socio-demographic characteristics including age, sex, education and living situation were obtained. The following clinical characteristics were assessed; the presence of chronic diseases, presence and severity of pain and use of medication. For assessment of chronic diseases, a self-rating questionnaire was used, that was shown to be independent of cognitive impairment or depressive symptomatology 28 . Presence of cardiovascular disease comprised cardiac disease, peripheral atherosclerosis and/or stroke. Pain experience was assessed with the 10 items of the self-report Chronic Graded Pain Scale (CGPS) ${ }^{29}$. Medication use was determined by assessing the medication that the 


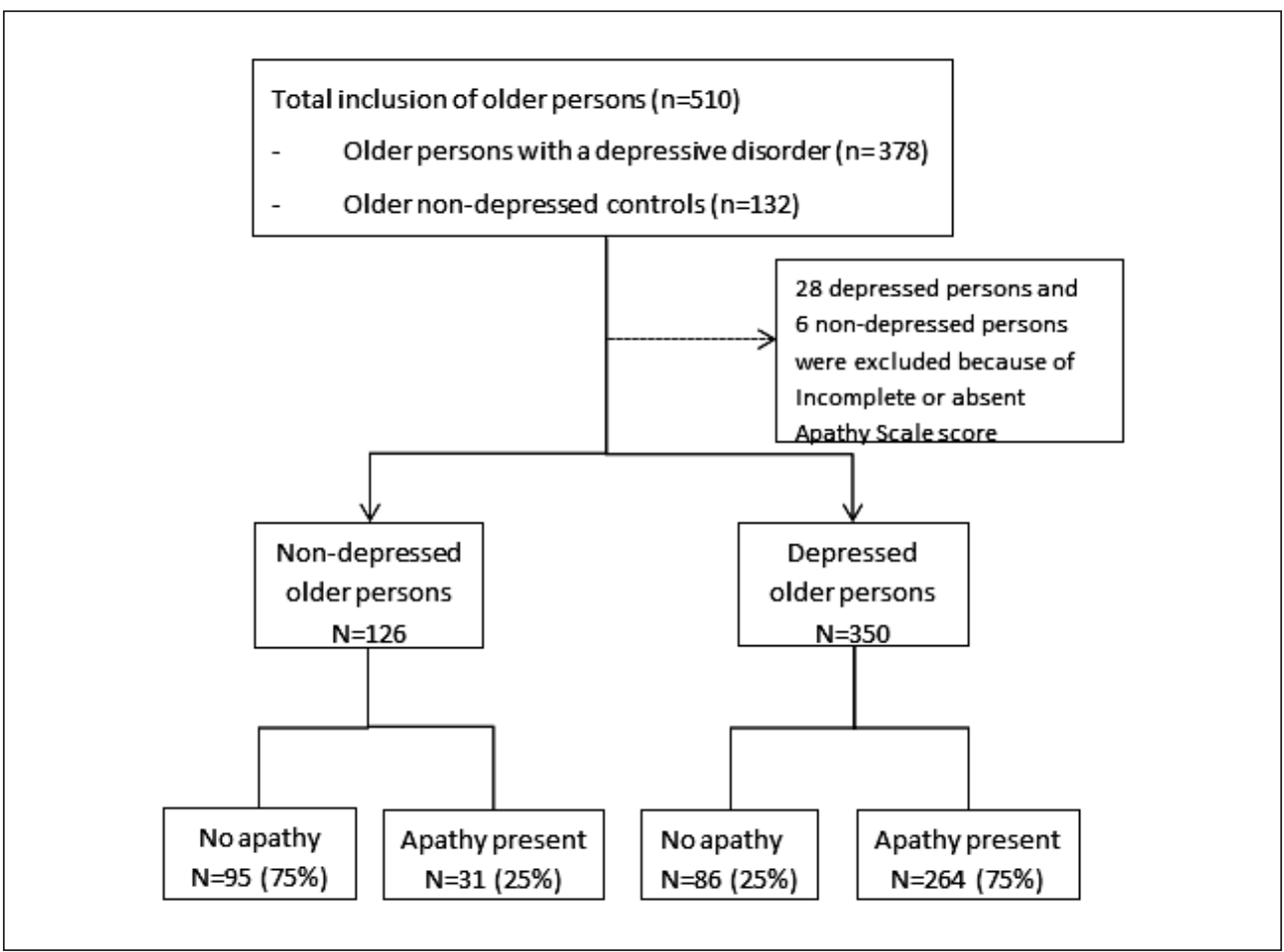

Figure 1. Flow chart included persons.

participants brought with them ${ }^{21}$, and classified using the Anatomical Therapeutic Chemical (ATC) Classification System ${ }^{30}$. Biological markers of immune function (Interleukin 6 and C-reactive protein levels) and nutritional status (albumin concentration) were assessed in fasting blood. Further, walking speed as a measure for frailty was determined by measuring the time in seconds needed to complete a six meter walk ${ }^{31}$.

\section{Statistical analyses}

All data are presented as numbers with percentages, medians with interquartile ranges (IQR) or means with standard deviations (SD) where appropriate. For group comparisons on apathy correlates, the Mann-Whitney $\mathrm{U}$ for continuous data was used, because of a non-parametric distribution, and $\chi^{2}$ tests were used for categorical data. Fisher's exact test was used when frequencies were lower than five in one or more cells.

Since values of CRP, IL6 and walking speed showed a skewed distribution, these were $\log _{\mathrm{e}}$-transformed. Multivariate regression analyses investigating independent correlates of apathy were done separately in the groups of depressed and non-depressed older persons, entering variables that showed a significance level of $<0.1$ in the univariate analyses, next to age and gender that were forced into the multivariate models. Odds ratios (ORs) and their 95\% confidence intervals $(95 \%$ CI $)$ were computed. A p-value $<0.05$ was considered statistically significant. Statistical analyses were performed with SPSS 20.0 for Windows (IBM). 


\section{Results}

Depressed $(\mathrm{n}=350)$ and non-depressed $(\mathrm{n}$ $=126$ ) older persons showed no significant difference in age ( $70 \pm 7$ and $71 \pm 7$ years, respectively) and gender distribution (62\% and $66 \%$ female gender, respectively) (data not shown). Apathy, as defined by a score $\geq 14$ on the Apathy Scale, was present in $75 \%(n=86)$ of the depressed older persons and in $25 \%$ ( $n$ $=31$ ) of the non-depressed older persons.

Table 1 shows the characteristics of depressed older persons with apathy compared to those without apathy. Apathy was associated with male gender and having had fewer years of education. Furthermore, IDS scores were significantly higher and walking speed slower in depressed older persons with apathy, compared to those without apathy.

Among non-depressed older persons, apathy was associated with higher age, fewer years of education and, additionally, with having less often a current partner (table 2). Furthermore, non-depressed older persons with apathy more often had cardiovascular diseases, used more psychotropic and analgesic medication, and had higher scores on the IDS and lower scores on the MMSE compared to non-depressed older persons without apathy. In addition, apathy was associated with significantly higher levels of CRP and IL6 and slower walking speed.

Table 3 and 4 show the independent correlates of apathy among both the depressed and non-depressed older persons. Independent correlates for apathy among depressed older persons were male gender, less education, and higher IDS scores. In addition, among non-depressed older persons, apathy was independently correlated to increased CRP level.

For sensitivity analysis, all multivariate analyses were repeated using cut-off scores of 13 and 15 on the Apathy Scale, respectively, which yielded similar results. Additionally, we analysed the correlation between the total Apathy Scale and IDS scores $(r=0.3)$, showing a 10 per cent shared variance only.

\section{Discussion}

Clinically relevant apathy was present in $75 \%$ of the depressed and $25 \%$ of the non-depressed older persons. In both depressed and non-depressed older persons, apathy was associated with male gender and less education. Additionally, apathy was strongly associated with the severity of depression in depressed persons and with a higher CRP level in nondepressed persons.

An occurrence of $75 \%$ for apathy, as was found in the depressed older persons is within the wide range of $42-96 \%$, reported in earlier studies $^{8,9,32}$. Also, the 11-27\% occurrence of apathy among non-depressed older persons is in line with most community studies ${ }^{13,19,20,33}$, although some studies reported lower percentages ${ }^{4}$. Our relatively high occurrence rate of apathy in both groups depressed and nondepressed people may be due to the use of the self-administered method to asses apathy. This may have led to higher scores, compared to observer-rated scores as was found in a study on self-report of the 15 -item version of the Geriatric Depression Scale ${ }^{34}$. Sensitive questions may be answered more truthfully when self-administered, since the interviewer's influence to give social desirable answers is absent. On the other hand, explanation of the items by an interviewer can solve misunderstandings, leading to more specific answers ${ }^{34}$.

In the depressed older group, presence of apathy was particularly associated with severity of depression, suggesting that the symptom apathy indicates more severe depres- 
Table 1

Characteristics of depressed older persons with and without apathy $(n=350)$.

$\begin{array}{lll}\begin{array}{l}\text { Apathy absent } \\ (\mathrm{n}=86,25 \%)\end{array} & \begin{array}{l}\text { Apathy present } \\ (\mathrm{n}=264,75 \%)\end{array}\end{array} \quad \mathrm{fd}(\mathrm{F}) \quad \mathrm{P}^{\dagger}$

\section{Sociodemographic characteristics}

\begin{tabular}{|c|c|c|c|c|c|c|}
\hline Age in years, mean (SD) & 70 & (8) & 71 & (7) & $348(0.70)$ & 0.20 \\
\hline Female gender & 65 & (76) & 166 & (63) & 1 & 0.04 \\
\hline Education in years & 10 & $(9-15)$ & 10 & $(9-11)$ & & 0.03 \\
\hline Current partner & 46 & $(54)$ & 139 & $(53)$ & 1 & 0.99 \\
\hline \multicolumn{7}{|l|}{ Clinical characteristics } \\
\hline Presence of chronic disease* & 26 & (30) & 101 & (38) & 1 & 0.20 \\
\hline Cardiovascular disease $^{\#}$ & 27 & (31) & 95 & (36) & 1 & 0.50 \\
\hline Diabetes Mellitus & 8 & (9) & 34 & (13) & 1 & 0.50 \\
\hline Arthritis/rheuma & 39 & (45) & 144 & (55) & 1 & 0.20 \\
\hline Chronic lung disease & 11 & (13) & 42 & (16) & 1 & 0.60 \\
\hline \multicolumn{7}{|l|}{ Presence of pain^ } \\
\hline Intensity & 40 & $(26-61)$ & 50 & $(33-63)$ & & 0.09 \\
\hline Disability & 25 & $(0-53)$ & 32 & $(3-63)$ & & 0.10 \\
\hline Medication use & 84 & (98) & 261 & (99) & 1 & 0.80 \\
\hline Psychotropic medication $^{\circ}$ & 66 & (77) & 215 & (81) & 1 & 0.20 \\
\hline Benzodiazepines & 27 & (31) & 109 & (41) & 1 & 0.30 \\
\hline Antidepressants & 58 & (67) & 197 & (75) & 1 & 0.20 \\
\hline Antipsychotics & 10 & (12) & 38 & (14) & 1 & 0.50 \\
\hline Analgesic medication $^{\mathrm{a}}$ & 24 & $(28)$ & 90 & (33) & 1 & 0.40 \\
\hline \multicolumn{7}{|c|}{ Neuropsychiatric characteristics } \\
\hline IDS score & 22 & $(15-31)$ & 31 & $(22-41)$ & & $<0.005$ \\
\hline AS score & 10 & $(8-12)$ & 19 & $(17-22)$ & & $<0.005$ \\
\hline MMSE score $\$$ & 28 & $(27-29)$ & 28 & $(27-29)$ & & 0.3 \\
\hline \multicolumn{7}{|l|}{$\overline{\text { Biological characteristics }}$} \\
\hline Albumine $(\mathrm{g} / \mathrm{l})$ & 42 & $(40-44)$ & 42 & $(40-45)$ & & 0.60 \\
\hline IL6 $(\mathrm{pg} / \mathrm{ml}) \S$ & 0.8 & $(0.6-1)$ & 0.8 & $(0.7-1)$ & $340(0.01)$ & 0.50 \\
\hline $\mathrm{CRP}(\mathrm{mg} / \mathrm{l}) \S$ & 1.7 & $(1.3-2.2)$ & 2.1 & $(1.8-2.4)$ & $336(0.60)$ & 0.30 \\
\hline Walking speed (sec.)§ & 6.4 & $(5.9-7)$ & 7.1 & $(6.7-7.4)$ & $344(0.30)$ & 0.03 \\
\hline
\end{tabular}

Data are presented as numbers (percentages), means (standard deviations) or medians (interquartile ranges), where appropriate.

IDS: Inventory of Depressive Symptomatology, 30-items self-rating ; AS: Apathy Scale, 14-items self-rating; MMSE: Mini Mental State Examination; IL6: Interleukin-6; CRP: C-reactive protein

$\dagger \mathrm{p}$-values by chi-square, t-test or Mann-Whitney where appropriate; when count $<5$, Fisher's exact test was used; *presence of chronic disease is defined by the median cut-off score of numbers of chronic diseases;

\#included coronar, vascular and cerebral;

^Pain intensity and disability scores as assessed with the Chronic Graded Pain Scale with scores 0-100 and higher scores indicating more intense or disabling pain;

${ }^{\circ}$ Psychotropic medication includes the use of benzodiazepines, antidepressants and antipsychotic drugs;

aAnalgesic includes the use of peripheral working analgesic medication, NSAID's and analid;

$\$$ subjects with Mini Mental Status Examination < 19 were excluded;

$\dagger p$-values by chi-square or Mann-Whitney where appropriate;

§geometric mean and 95\% CI. 
Table 2

Characteristics of non-depressed older persons with and without apathy $(\mathrm{n}=126)$.

$$
\begin{array}{cccc}
\begin{array}{c}
\text { Apathy absent } \\
(\mathrm{n}=95,75 \%)
\end{array} & \begin{array}{c}
\text { Apathy present } \\
(\mathrm{n}=31,25 \%)
\end{array} & \mathrm{fd}(\mathrm{F}) & \mathrm{P}^{\dagger}
\end{array}
$$

\begin{tabular}{|c|c|c|c|c|c|c|}
\hline \multicolumn{7}{|l|}{ Sociodemographic characteristics } \\
\hline Age in years, mean $(\mathrm{SD})$ & 69 & (6) & 73 & (8) & $42(6.1)$ & 0.030 \\
\hline Female gender & 62 & $(65)$ & 16 & $(52)$ & 1 & 0.300 \\
\hline Education in years & 12 & $(10-15)$ & 11 & $(9-12)$ & & 0.001 \\
\hline Current partner & 77 & $(81)$ & 19 & $(61)$ & 1 & 0.045 \\
\hline \multicolumn{7}{|l|}{ Clinical characteristics } \\
\hline Presence of Chronic disease present* & 41 & (43) & 13 & $(42)$ & 1 & 1 \\
\hline Cardiovascular disease $^{\#}$ & 17 & $(18)$ & 13 & $(42)$ & 1 & 0.010 \\
\hline Diabetes Mellitus & 11 & $(12)$ & 5 & (16) & 1 & 0.700 \\
\hline Arthritis/rheuma & 44 & $(46)$ & 16 & $(52)$ & 1 & 0.800 \\
\hline Chronic lung disease & 8 & $(8)$ & 1 & (3) & 1 & 0.600 \\
\hline \multicolumn{7}{|l|}{ Pain $^{\wedge}$} \\
\hline intensity & 30 & $(0-43)$ & 30 & $(10-53)$ & & 0.400 \\
\hline disability & 0 & $(0-20)$ & 0 & $(0-37)$ & & 0.900 \\
\hline Medication use & 79 & $(83)$ & 28 & $(90)$ & 1 & 0.500 \\
\hline Psychotropic medication $^{\circ}$ & 1 & $(1)$ & 4 & (13) & 1 & $<0.005$ \\
\hline Benzodiazepines & 1 & (1) & 2 & (6) & 1 & 0.300 \\
\hline Antidepressants & 0 & $(0)$ & 2 & (6) & 1 & 0.060 \\
\hline Antipsychotics & 0 & $(0)$ & 0 & $(0)$ & 1 & - \\
\hline Analgesic medication & 14 & $(15)$ & 11 & $(36)$ & 1 & 0.020 \\
\hline \multicolumn{7}{|l|}{ Neuropsychiatric characteristics } \\
\hline IDS score & 6 & $(4-9)$ & 7 & $(5-12)$ & & 0.040 \\
\hline AS score & 9 & $(6-11)$ & 16 & $(14-17)$ & & $<0.005$ \\
\hline MMSE score $\$$ & 29 & $(28-30)$ & 28 & $(27-29)$ & & 0.040 \\
\hline \multicolumn{7}{|l|}{ Biological characteristics } \\
\hline Albumin $(\mathrm{g} / \mathrm{l})$ & 42 & $(40-45)$ & 43 & $(41-46)$ & & 0.300 \\
\hline IL6 (pg/ml)§ & 0.7 & $(0.6-0.9)$ & 1.1 & $(0.8-1.6)$ & $121(1.2)$ & 0.049 \\
\hline $\mathrm{CRP}(\mathrm{mg} / \mathrm{l}) \S$ & 1.4 & $(1.1-1.7)$ & 2.8 & $(1.96-3.9)$ & $119(0.1)$ & $<0.005$ \\
\hline Walking speed (sec.)§ & 6 & $(5.6-6.4)$ & 6.8 & $(6-7.6)$ & $123(0.4)$ & 0.030 \\
\hline
\end{tabular}

Data are presented as numbers (percentages), means (standard deviations) or medians (interquartile ranges), where appropriate.

IDS: Inventory of Depressive Symptomatology, 30-items self-rating ; AS: Apathy Scale, 14-items self-rating; MMSE: Mini Mental State Examination; IL6: Interleukin-6; CRP: C-reactive protein

$\dagger p$-values by chi-square, t-test or Mann-Whitney where appropriate; when count $<5$, Fisher's exact test was used; *presence of chronic disease is defined by the median cut-off score of numbers of chronic diseases;

\#included coronar, vascular and cerebral;

^Pain intensity and disability scores as assessed with the Chronic Graded Pain Scale with scores 0-100 and higher scores indicating more intense or disabling pain;

${ }^{\circ}$ Psychotropic medication includes the use of benzodiazepines, antidepressants and antipsychotic drugs;

aAnalgesic includes the use of peripheral working analgesic medication, NSAID's and analid;

$\$$ subjects with Mini Mental Status Examination < 19 were excluded;

$\dagger p$-values by chi-square or Mann-Whitney where appropriate;

§geometric mean and 95\% CI. 
Table 3

Independent correlates of apathy in depressed older persons $(n=350)$.

\begin{tabular}{lccrr} 
& \multicolumn{4}{c}{ Multivariate analyses } \\
\cline { 2 - 5 } & OR & $95 \% \mathrm{CI}$ & Wald & \multicolumn{1}{c}{$\mathrm{P}$} \\
\hline Age in years & 1.00 & $0.99-1.1$ & 2.3 & 0.100 \\
Female gender & 0.40 & $0.2-0.7$ & 8.8 & $<0.005$ \\
Education in years & 0.90 & $0.8-0.99$ & 5.0 & 0.030 \\
Pain intensity & 0.99 & $0.98-1.0$ & 0.7 & 0.400 \\
IDS & 1.10 & $1.0-1.1$ & 22.2 & $<0.005$ \\
Log $_{\mathrm{e}}$ walking speed (sec.) & 1.30 & $0.5-2.95$ & 0.3 & 0.600 \\
\hline
\end{tabular}

Multivariate analyses using variables that showed a significance level of $\mathrm{p}<0.1$ on the univariate analyses. IDS: Inventory of Depressive Symptomatology, 30-items self-rating.

Table 4

Independent correlates of apathy in non-depressed older persons $(n=126)$.

\begin{tabular}{lcccc} 
& \multicolumn{4}{c}{ Multivariate analyses } \\
\cline { 2 - 5 } & OR & $95 \%$ CI & Wald & P \\
\hline Age in years & 1.03 & $0.95-1.1$ & 0.500 & 0.500 \\
Female gender & 0.20 & $0.08-0.8$ & 5.400 & 0.020 \\
Education in years & 0.80 & $0.7-0.9$ & 6.900 & 0.008 \\
Current partner & 1.80 & $0.5-6.9$ & 0.700 & 0.400 \\
Cardiovascular disease present & 1.30 & $0.4-4.6$ & 0.200 & 0.700 \\
Use of analgesic medication & 1.80 & $0.5-6.8$ & 0.800 & 0.400 \\
IDS & 1.10 & $0.96-1.2$ & 1.600 & 0.200 \\
MMSE & 0.96 & $0.7-1.4$ & 0.06 & 0.800 \\
Log $_{\mathrm{e}}$ CRP (mg/l) & 1.80 & $1.0-3.1$ & 4.100 & 0.040 \\
Log $_{\mathrm{e}}$ IL6 (pg/ml) & 0.80 & $0.3-2.2$ & 0.200 & 0.600 \\
Log $_{\mathrm{e}}$ walking speed (sec.) & 1.10 & $0.1-7.8$ & 0.004 & 0.900 \\
\hline
\end{tabular}

Multivariate analyses using variables that showed a significance level of $\mathrm{p}<0.1$ on the univariate analyses. IDS: Inventory of Depressive Symptomatology, 30-items self-rating; MMSE: Mini Mental State Examination. IL6: Interleukin-6; CRP: C-reactive protein.

sion, which has been found in many studies before $8,16,32,35$. Also, apathy as a syndrome in its own right may be distinguished from depression by the absence of mood-related symptoms ${ }^{36,37}$. Further, different etiologies for apathy as a distinct syndrome and late-life depression have been found among older persons ${ }^{5,19,20,38}$. Also, the treatment of apathy differs from depression in that antidepressants will treat depression but not always ap- 
athy ${ }^{9,39}$. So, it remains debatable whether apathy in depression can be regarded as a distinct behavioral syndrome.

Among non-depressed older persons, CRP was one of the independent correlates of apathy, which corresponds with the results of a large community-based, cross-sectional study among 3,534 older persons aged 70-79 years $^{20}$; but contrasts with the findings in the community-based, longitudinal Leiden 85Plus Study among 460 older persons $(\geq 85$ year $)^{5}$. Our results may be different from the latter due to our population being younger, the use of the well-validated Apathy Scale, and considering continues CRP values instead of tertiles ${ }^{5,20}$.

Male gender was independently correlated to apathy in both the depressed and non-depressed older persons, which has been reported previously only among non-depressed community-based older persons (mean age 69.9 years $^{6}$, although not consistently ${ }^{33}$. Also, less education as independent correlate of apathy has been reported before in several studies among community-dwelling older persons ${ }^{4,19}$. Possibly, having had more education protects not only against dementia ${ }^{40}$, but also against apathy in late life, as a result of greater cognitive reserve.

Depression and apathy were diagnosed using well known validated measures which are an important strength of our study, whereas presence and similar characteristics of apathy in a large group of depressed and non-depressed general-based older persons were investigated. However, an important limitation of our study is the cross-sectional design which prevents drawing causal inferences. Furthermore, our population was relatively young and, therefore, our results cannot be generalized to older old people. We are also aware of the fact that a conceptual problem is present, since depression and apathy symptoms overlap, especially with regard to motivational symptoms, but in our study the overlap of the Apathy Scale and IDS was very low. Finally, although we included both mildly and severely depressed older people selection bias may have occurred, since older persons with most severe depression and apathy were not able to participate in the study.

In conclusion, this study showed that apathy occurred frequently among both depressed and non-depressed older persons. Among depressed older persons, apathy appeared to be a symptom of more serious depression, whereas among non-depressed persons apathy was associated with increased CRP, a marker for inflammation, suggesting a different aetiology for apathy as a syndrome in its own right. Importantly, information about apathy and its possible concomitants may result in a better understanding and treatment of apathy.

\section{Disclosure}

The authors declare that they have no conflicts of interest concerning this article. The authors have no financial relationships with any organizations that might have an interest in the submitted work in the previous three years, no other relationships or activities that could appear to have influenced the submitted work.

\section{Author contributions}

- Study concept and design: Comijs, Naarding, De Waal, Van der Mast

- Acquisition of data: Comijs, Naarding, De Waal, Van der Mast 
- Analysis and interpretation of data: Groeneweg-Koolhoven, Comijs, Naarding, De Waal, Van der Mast

- Drafting of the manuscript: GroenewegKoolhoven, Comijs, Naarding, De Waal, Van der Mast

- Critical revision of the manuscript for important intellectual content: Groeneweg-Koolhoven, Comijs, Naarding, De Waal, Van der Mast

- Final approval of the version to be published: Groeneweg-Koolhoven, Comijs, Naarding, De Waal, Van der Mast

- Guarantors: Van der Mast

\section{Acknowledgements}

The infrastructure for NESDO was funded through the Fonds NutsOhra (project 0701065), Stichting tot Steun VCVGZ, NARSAD The Brain and Behavior Research Fund (Grand Id 41080), and the participating universities and mental health care organizations (VU University Medical Center, Leiden University Medical Center, University Medical Center Groningen, Radboud University Nijmegen Medical Center and GGZ Ingeest, GGNet, GGZ Nijmegen, GGZ Rivierduinen, Lentis and Parnassia). The funders had no role in the study design or in the collection, analysis, interpretation and reporting of data.

\section{References}

1. Marin RS. Apathy: A neuropsychiatric syndrome. J Neuropsychiatry Clin Neurosci. 1991; 3(3): 243-54. Review.

2. Starkstein SE, Leentjens AF. The nosological position of apathy in clinical practice. J Neurol Neurosurg Psychiatry. 2008; 79(10): 1088-92.
3. Robert P, Onyike CU, Leentjens AF Dujardin K, Aalten $\mathrm{P}$, Starkstein $\mathrm{S}$ et al. Proposed diagnostic criteria for apathy in Alzheimer's disease and other neuropsychiatric disorders. Eur Psychiatry. 2009; 24(2): 98-104.

4. Onyike CU, Sheppard JM, Tschanz JT, Norton MC, Green RC, Steinberg M et al. Epidemiology of apathy in older adults: The Cache County Study. Am J Geriatr Psychiatry. 2007; 15(5): 365-75.

5. Maas DW, van der Mast RC, de Craen AJ. Increased Creactive protein is not associated with apathy: The Leiden 85 Plus Study. Int J Geriatr Psychiatry. 2009; 24(11): 1177-84.

6. Brodaty H, Altendorf A, Withall A, Sachdev P. Do people become more apathetic as they grow older? A longitudinal study in healthy individuals. Int Psychogeriatr. 2010; 22(3): 426-36.

7. Lyketsos CG, Steinberg M, Tschanz JT, Norton MC, Steffens DC, Breitner JC. Mental and behavioral disturbances in dementia: Findings from the Cache County Study on Memory in Aging. Am J Psychiatry. 2000; 157(5): 708-14.

8. Lampe IK, Heeren TJ. Is apathy in late-life depressive illness related to age-at-onset, cognitive function or vascular risk? Int Psychogeriatr. 2004; 16(4): 481-6.

9. Wongpakaran N, van Reekum R, Wongpakaran T, Clarke D. Selective serotonin reuptake inhibitor use associates with apathy among depressed elderly: A case-control study. Ann Gen Psychiatry. 2007; 6: 7.

10. Mulin E, Leone E, Dujardin K, Delliaux M, Leentjens A, Nobili F et al. Diagnostic criteria for apathy in clinical practice. Int J Geriatr Psychiatry. 2011; 26(2): 158-65.

11. Levy ML, Cummings JL, Fairbanks LA, Masterman D, Miller BL, Craig AH et al. Apathy is not depression. J Neuropsychiatry Clin Neurosci. 1998; 10(3): 314-9.

12. Lavretsky H, Ballmaier M, Pham D, Toga A, Kumar A. Neuroanatomical characteristics of geriatric apathy and depression: A magnetic resonance imaging study. Am J Geriatr Psychiatry. 2007; 15(5): 386-94.

13. Groeneweg-Koolhoven I, de Waal MW, van der Weele GM, Gussekloo J, van der Mast RC. Quality of life in community-dwelling older persons with apathy. Am J Geriatr Psychiatry. 2014; 22(2): 186-94.

14. Vinkers DJ, Stek ML, Gussekloo J, van der Mast RC, Westendorp RG. Does depression in old age increase only cardiovascular mortality? The Leiden 85-plus Study. Int J Geriatr Psychiatry. 2004; 19(9): 852-7.

15. Lavretsky H, Zheng L, Weiner MW, Mungas D, Reed $\mathrm{B}$, Kramer JH et al. Association of depressed mood and mortality in older adults with and without cognitive impairment in a prospective naturalistic study. Am J Psychiatry. 2010; 167(5): 589-97. 
16. Starkstein SE, Petracca G, Chemerinski E, Kremer J. Syndromic validity of apathy in Alzheimer's disease. Am J Psychiatry. 2001; 158(6): 872-7.

17. Lyketsos CG, Lopez O, Jones B, Fitzpatrick AL, Breitner J, DeKosky S. Prevalence of neuropsychiatric symptoms in dementia and mild cognitive impairment: Results from the cardiovascular health study. JAMA. 2002; 288(12): 1475-83.

18. Brodaty H, Sachdev PS, Withall A, Altendorf A, Valenzuela MJ, Lorentz L. Frequency and clinical, neuropsychological and neuroimaging correlates of apathy following stroke - the Sydney Stroke Study. Psychol Med. 2005; 35(12): 1707-16.

19. van der Mast RC, Vinkers DJ, Stek ML, Bek MC, Westendorp RG, Gussekloo J et al. Vascular disease and apathy in old age. The Leiden 85-Plus Study. Int J Geriatr Psychiatry. 2008; 23(3): 266-71.

20. Ligthart SA, Richard E, Fransen NL, Eurelings LS, Beem L, Eikelenboom P et al. Association of vascular factors with apathy in community-dwelling elderly individuals. Arch Gen Psychiatry. 2012; 69(6): 636-42.

21. Comijs HC, van Marwijk HW, van der Mast RC, Naarding P, Oude Voshaar RC, Beekman AT et al. The Netherlands study of depression in older persons (NESDO); A prospective cohort study. BMC Res Notes. 2011; 4: 524.

22. Wittchen HU, Robins LN, Cottler LB, Sartorius N, Burke JD, Regier D. Cross-cultural feasibility, reliability and sources of variance of the Composite International Diagnostic Interview (CIDI). The Multicentre WHO/ADAMHA Field Trials. Br J Psychiatry. 1991; 159: 645-53, 658. Erratum in: Br J Psychiatry. 1992; 160: 136.

23. Starkstein SE, Mayberg HS, Preziosi TJ, Andrezejewski P, Leiguarda R, Robinson RG. Reliability, validity, and clinical correlates of apathy in Parkinson's disease. J Neuropsychiatry Clin Neurosci. 1992; 4(2): 134-9.

24. Pedersen KF, Alves G, Larsen JP, Tysnes OB, Moller SG, Bronnick K. Psychometric properties of the Starkstein Apathy Scale in patients with early untreated Parkinson disease. Am J Geriatr Psychiatry. 2012; 20(2): 142-8.

25. van Reekum R, Stuss DT, Ostrander L. Apathy: Why care? J Neuropsychiatry Clin Neurosci. 2005; 17(1): 7-19. Review.

26. Rush AJ, Gullion CM, Basco MR, Jarrett RB, Trivedi MH. The Inventory of Depressive Symptomatology (IDS): Psychometric properties. Psychol Med. 1996; 26(3): 477-86.

27. Mackin RS, Ayalon L, Feliciano L, Arean PA. The sensitivity and specificity of cognitive screening instruments to detect cognitive impairment in older adults with se- vere psychiatric illness. J Geriatr Psychiatry Neurol. 2010; 23(2): 94-9.

28. Kriegsman DM, Penninx BW, van Eijk JT, Boeke AJ, Deeg DJ. Self-reports and general practitioner information on the presence of chronic diseases in community dwelling elderly. A study on the accuracy of patients' self-reports and on determinants of inaccuracy. J Clin Epidemiol. 1996; 49(12): 1407-17.

29. Von KM, Miglioretti DL. A prognostic approach to defining chronic pain. Pain. 2005; 117(3): 304-13.

30. Norwegian Institute of public health. Anatomical Therapeutic Chemical Classification with used daydoses. WHO Collaborating Centre for Drug Statistics. 2011 http://www.whocc.no/atc_ddd_index/.

31. Guralnik JM, Ferrucci L, Pieper CF, Leveille SG, Markides KS, Ostir GV et al. Lower extremity function and subsequent disability: Consistency across studies, predictive models, and value of gait speed alone compared with the short physical performance battery. J Gerontol A Biol Sci Med Sci. 2000; 55(4): M221-31.

32. Marin RS, Firinciogullari S, Biedrzycki RC. Group differences in the relationship between apathy and depression. J Nerv Ment Dis. 1994; 182(4): 235-9.

33. Clarke DE, Ko JY, Lyketsos C, Rebok GW, Eaton WW. Apathy and cognitive and functional decline in community-dwelling older adults: Results from the Baltimore ECA longitudinal study. Int Psychogeriatr. 2010; 22(5): 819-29.

34. de Waal MW, van der Weele GM, van der Mast RC, Assendelft WJ, Gussekloo J. The influence of the administration method on scores of the 15-item Geriatric Depression Scale in old age. Psychiatry Res. 2012; 197(3): 280-4.

35. Mehta M, Whyte E, Lenze E, Hardy S, Roumani Y, Subashan P et al. Depressive symptoms in late life: Associations with apathy, resilience and disability vary between young-old and old-old. Int J Geriatr Psychiatry. 2008; 23(3): 238-43.

36. Marin RS, Firinciogullari S, Biedrzycki RC. The sources of convergence between measures of apathy and depression. J Affect Disord. 1993; 28(2): 117-24.

37. Leontjevas R, van HS, Waterink W, Mulders A. Apathy and depressive mood in nursing home patients with early-onset dementia. Am J Alzheimers Dis Other Demen. 2009; 24(4): 341-8.

38. Yuen GS, Bhutani S, Lucas BJ, Gunning FM, AbdelMalak B, Seirup JK et al. Apathy in late-life depression: Common, persistent, and disabling. Am J Geriatr Psychiatry. 2015; 23(5): 488-94. 
39. Yuen GS, Gunning FM, Woods E, Klimstra SA, Hoptman MJ, Alexopoulos GS. Neuroanatomical correlates of apathy in late-life depression and antidepressant treatment response. J Affect Disord. 2014; 166: 179-86.

40. Meng X, D'Arcy C. Education and dementia in the context of the cognitive reserve hypothesis: A systematic review with meta-analyses and qualitative analyses. PLoS One. 2012; 7(6): e38268. Review.
* Corresponding author: Isis Groeneweg-Koolhoven Department of Psychiatry, B1-P Leiden University Medical Center PO Box 9600, 2300 RC Leiden The Netherlands Tel. 31-71-5263785

Fax: 31-71-5248156

E-mail: i.groeneweg-koolhoven@lumc.nl 